Breaking the barriers between intelligence, investigation and evaluation: a continuous approach to define the contribution and scope of forensic science

Simon Baechler ${ }^{1,2,3}$ \& Marie Morelato ${ }^{4 *}$, Simone Gittelson ${ }^{4}$, Simon Walsh ${ }^{5}$, Pierre Margot ${ }^{1}$, Claude Roux ${ }^{4}$, Olivier Ribaux ${ }^{1}$

\author{
1 Ecole des Sciences Criminelles, Université de Lausanne, 1015 Lausanne, Switzerland \\ 2 Forensic science unit, Police neuchâteloise, Switzerland \\ 3 Forensic Research Group (LRC), Université du Québec à Trois-Rivières, Canada \\ 4 Centre for Forensic Science, University of Technology, Sydney, Broadway, NSW, Australia \\ 5 Specialist Operations, Australian Federal Police, Canberra, NSW, Australia
}

Baechler, S., Morelato, M., Gittelson, S., Walsh, S., Margot, P., Roux, C., \& Ribaux, O. (2020). Breaking the barriers between intelligence, investigation and evaluation: a continuous approach to define the contribution and scope of forensic science.

Forensic science international, 309. doi:10.1016/j.forsciint.2020.110213 


\title{
Breaking the barriers between intelligence, investigation and evaluation: a continuous approach to define the contribution and scope of forensic science
}

\begin{abstract}
Forensic science has been evolving towards a separation of more and more specialised tasks, with forensic practitioners increasingly identifying themselves with only one sub-discipline or task of forensic science. Such divisions are viewed as a threat to the advancement of science because they tend to polarise researchers and tear apart scientific communities. The objective of this article is to highlight that a piece of information is not either intelligence or evidence, and that a forensic scientist is not either an investigator or an evaluator, but that these notions must all be applied in conjunction to successfully understand a criminal problem or solve a case.
\end{abstract}

To capture the scope, strength and contribution of forensic science, this paper proposes a progressive but non-linear continuous model that could serve as a guide for forensic reasoning and processes. In this approach, hypothetico-deductive reasoning, iterative thinking and the notion of entropy are used to frame the continuum, situate forensic scientists' operating contexts and decision points. Situations and examples drawn from experience and practice are used to illustrate the approach.

The authors argue that forensic science, as a discipline, should not be defined according to the context it serves (i.e. an investigation, a court decision or an intelligence process), but as a general, scientific and holistic trace-focused practice that contributes to a broad range of goals in various contexts. Since forensic science does not work in isolation, the approach also provides a useful basis as to how forensic scientists should contribute to collective and collaborative problem-solving to improve justice and security. 


\section{Introduction}

Forensic science has been evolving towards a separation of more and more specialised tasks, with forensic practitioners increasingly identifying themselves with only one sub-discipline or task of forensic science. Departments and professionals in practice are increasingly labelled and siloed. This is illustrated by the dominant conception of forensic science as a patchwork of disciplines ("forensics") [1], and by the lack of a universally recognised role for generalist forensic scientists [2].

We have observed that some forensic science departments, professionals and research projects are increasingly placing themselves in a single, isolated category of dichotomies that were never intended to separate scientists or items. For example, we have observed practitioners seeing themselves as being either an "investigator" or an "evaluator", failing to see that these roles are not descriptions of people, but of two different forms of reasoning that a forensic scientist engages in [3]. We have observed practitioners calling a piece of information as being either "intelligence" or "evidence", failing to see the commonalities since both are a piece of information that has to be combined and put into perspective with alternative pieces of information in order to understand criminal problems, solve crimes and support decision-making at various levels [4, 5]. Along the same lines as the concerns raised by [1,2], attitudes such as "That is intelligence, I won't forward it to partners or other stakeholders as they may misinterpret it and include it in a formal report" ${ }^{1}$ or "They are into evidence evaluation, I'm into forensic intelligence" represent an emerging threat to forensic science as a whole by creating barriers or comfortable zones, often framed into standards and letting science, pragmatism and holism out of the perspective. Such attitudes impede information sharing between forensic scientists working on different aspects of the same case or criminal problem, and ultimately cause linkage blindness and the wall effect $[7,8]$. In the academic world, the number of specialised forensic science journals, conferences and education programs has increased over the years. In parallel, audiences of separate streams within general forensic science conferences tend to become watertight. Training manuals and guidelines contribute to making these separations a norm [9-11]. Although the initial aim of these separations and delineations was to structure the role and positioning of the forensic practitioners, they have progressively become prescriptive and have strengthened the silos. They have blurred the overall picture for forensic scientists or external observers, and have weakened forensic science identity at a time when it faces unprecedented challenges and scrutiny. Depending on how it is implemented, any delineation runs the risk of concealing underlying transversal commonalities, hampering iterative thinking and leading to a disconnection between the multiple and polymorphic activities and roles of forensic science towards security and justice. Such divisions are viewed as a threat to the advancement of science because they tend to polarise researchers and tear apart scientific communities [12-15].

The objective of this article is to highlight that a piece of information is not either intelligence or evidence, and that a forensic scientist is not either an investigator or an evaluator, but that these notions must all be applied in conjunction to successfully understand a criminal problem, solve a case or an inquiry, or support decisions. The "large measure of overlap" between dichotomous categories is occasionally recognised [16] but often neglected, undiscussed or considered as marginal. To fill this gap and to capture the scope, strength and contribution of forensic science, this paper proposes a progressive, non-linear and continuous model that could serve as an overarching guide for forensic reasoning and processes. This model attempts to account for and conciliate the various roles of

\footnotetext{
${ }^{1}$ As an example, in some countries, links between drug seizures or shoe marks are qualified as intelligence and therefore are not reported to investigators, prosecutors or to the Court as forensic practitioners fear that they may be misinterpreted by a decision maker. A similar issue has been reported regarding the transnational exchange of DNA profiles (see reference [6], pp. 250-251).
} 
forensic scientists, and facilitate the emergence of "a generalist scientist and approach" and of a "holistic philosophy" [2] called for by several authors [1, 15, 17-20]. The model includes the overlapping zones between these roles, making these interfaces much more central than marginal. It also underlines that forensic scientists do not work in isolation [21], providing guidance as to how to engage forensic science in collective and collaborative problem-solving for justice and security purposes. Forensic science and its underlying models are too often defined or perceived through the lens of the existing organisations and their structure. This article attempts to reverse this paradigm and focuses on the science and concepts that transcend operational contexts ${ }^{2}$. In the proposed approach, hypothetico-deductive reasoning, iterative thinking and the notion of entropy are used to frame the non-linear continuum, and situate forensic scientists' operating contexts and decision points. Situations and examples drawn from casework experience are used to illustrate the model, underlining the continuity and the iterative character of forensic scientists' contributions.

\section{A model to describe forensic science reasoning and process}

Figure 1 presents the model that aims to describe and capture the progressive, continuous and nonlinear nature of the practice of forensic science, and its underlying reasoning. It depicts forensic science as a holistic trace-focused practice anchored in a scientific approach $[2,22]$ that may contribute to a broad range of goals in various contexts [4, 23-25]. The model includes the zones where evidence, intelligence, investigation and evaluation work as complementary features of the process. This model exists irrespective of time as it is possible (often advisable) to go back at any stage, hence the iterative character of the process. Key notions underpinning the model are defined below.

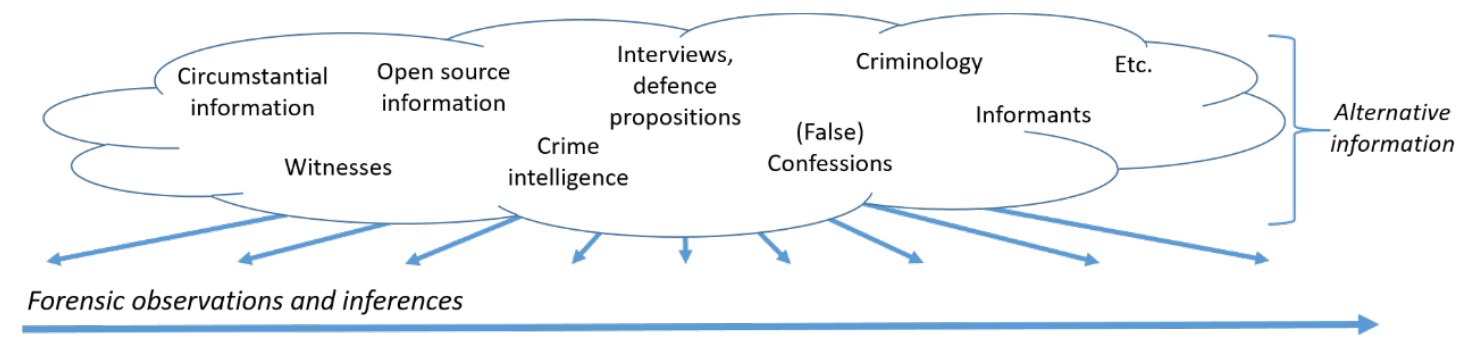

Entropy

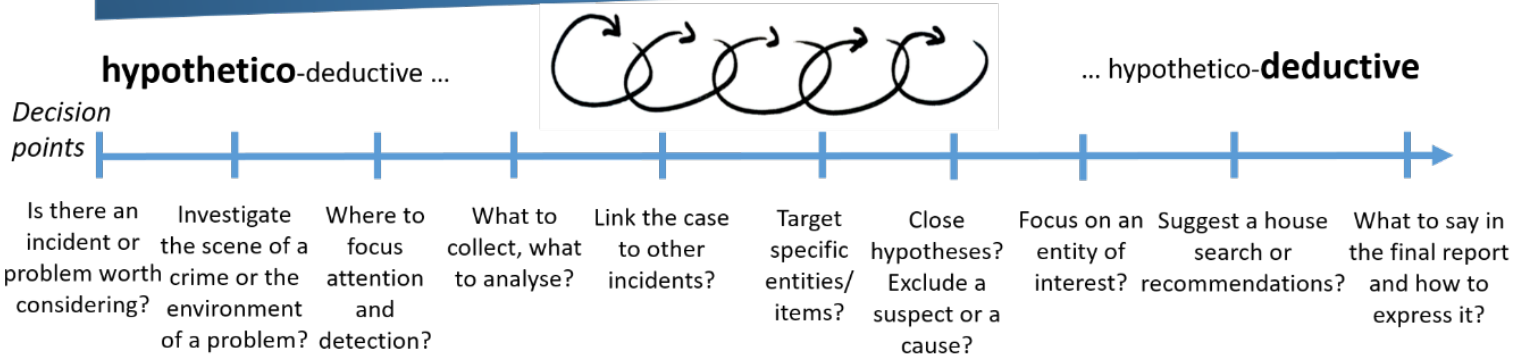

Figure 1. A continuous model to describe the scope of forensic science

\subsection{Entropy}

The notion of entropy relates to the state of disorder, chaos or uncertainty of a given system or situation. In information theory, maximum entropy principle is an inference principle used to describe a system on the basis of the (imperfect) information available [26]. It relates to the amount of uncertainty about an event. Entropy can also be viewed by analogy to its thermodynamic definition,

\footnotetext{
${ }^{2}$ Operational contexts can vary depending on the country, jurisdiction, procedures, law, organisation, political context and the roles of the various stakeholders.
} 
namely a measure of the changes a system has undergone from the previous state to the final state. In both information theory and thermodynamics, entropy can be described as maximal when all entities are equally probable, and we believe that this notion is useful to frame forensic processes and guide decisions. At the beginning of the forensic science process, such as at the start of a case or when one starts to manage a criminal problem, entropy and disorder prevails since all causes, explanations and scenarios are possible. Many hypotheses and avenues are open and equally likely (maximum entropy). At this stage, "forensic scientists are like drivers in the mist" [27]. They do not know exactly what they are looking for, what will be relevant or pivotal, or whether they are the best qualified to address the situation at hand. Their capability and situational awareness are uncertain [28]. Once forensic scientists start investigating, detecting, collecting data, and gathering more information, they evolve towards a more ordered, structured and certain state of knowledge. Hypotheses are progressively refined, some are excluded, others are put forward and analogies with similar cases or traces are drawn. This gradually crystallises knowledge and informs the explanation of what happened. By accumulating forensic observations and inferences, forensic scientists contribute to reduce entropy and increase the understanding of the criminal event, incident or criminal problem. The decrease in entropy throughout the process reflects the aim of forensic endeavours, namely to reconstruct the unity of action, time and place [29].

It is important to underline that entropy does not relate to the situation itself (i.e. an event happened and traces were left) but to the forensic scientist's understanding and perception of that situation (i.e. the forensic scientist tries to decipher what happened). In other words, entropy does not describe a state of nature but a state of mind. Interestingly, the change towards a decreased entropy tends to be reflected by the pictorial language used daily by practitioners, with expressions such as "the initial phase of chaos", "to close doors" or "to put the pieces of the puzzle together". However, it means that any piece that does not fit a causal determination or explanation needs another storyline, or the finding of a missing element or a reason for the disagreeing element(s). This constant insecurity is one of the difficulties faced by many traditional scientists and investigators: facts cannot be tested in the classical manner of experimental science. A new reasonable framework has to be developed that offers the most reasonable (or probable) explanation (see section 2.3).

\subsection{Hypothetico-deductive reasoning}

The inference processes behind the continuous model may be best described by a specific kind of hypothetico-deductive reasoning ${ }^{3}$, detailed in $[1,30]$. It combines the development of hypotheses based on observations with the testing of these hypotheses through experiments or further observations, in a cyclic manner [17, 23, 25, 31-33], following a systematic and scientific approach [2, 22]. The peculiarity of the forensic processing of a case or criminal problem is that it shifts progressively its emphasis from the development of hypotheses (through abduction) to the confirmation/invalidation of them (through a more deductive approach as to the cause of the observed results), thus decreasing the entropy (Figure 2).

During the early and most entropic stages, an exploratory, proactive and abductive attitude is required to draw, process, reason on and test an unlimited set of hypotheses [34]. The capability of imagining a large range of possibilities to explain available information and a lateral thinking ability are sought $[15,35-38]$. Then, the understanding of the situation or case moves towards less entropic stages, where a more informed, reliable, reactive and deductive position is adopted to address a progressively restricted set of stabilised propositions [35]. In other words, the search for potential causes from

\footnotetext{
${ }^{3}$ The logic is not purely deductive as the premises are not known but rather assumed and thus the conclusions not certain. However, this term is used for pragmatic reasons here.
} 
observations (effects) through abductive reasoning leaves an increasing place to a deductive reasoning (i.e. "if cause $X$ is true, then...") that assesses the probability of the effects in light of alternative causes.

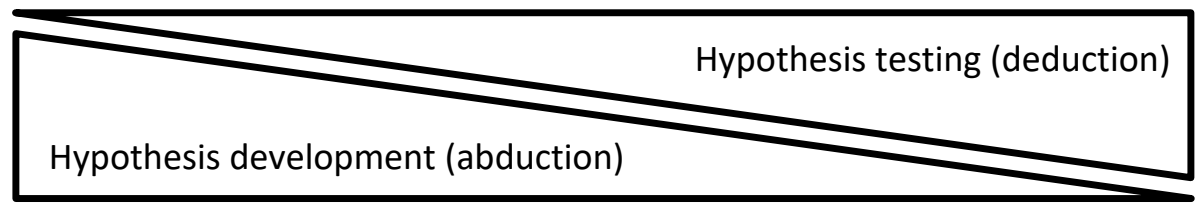

Figure 2. Hypothetico-deductive reasoning: progressive shift in emphasis [39]

As an illustration, let us consider a forensic scientist called to examine the scene of a burglary. Even before arriving at the scene, the forensic scientist will develop a large number of hypotheses. These hypotheses are not based on direct observations by the forensic scientist but on the information provided during the call, general knowledge about crime (mainly derived from education, experience, intelligence about the current crime environment, and, more generally, criminological theories [40]). Upon arrival at the scene, to assess and potentially extend these initial hypotheses, the forensic scientist may have a look at the conchoidal lines of the broken window (the direction of the force to break the window may suggest a staged burglary if it comes from the inside), and examine the floors for the presence of extraneous shoe marks. Then, further or more detailed hypotheses can be developed, such as the burglary was committed by an opportunistic offender or by an insider who knew exactly where to find the loot. Such a hypothesis may come into mind if the entry point took advantage of a hidden vulnerability, or if the hidden safe was found by the burglar without evidence of an extensive search of the premise. To support this causal hypothesis, the forensic scientist may have a look at shoe marks on the floor and check out whether or not they lead to the safe directly. If so, the hypothesis that an employee might be the offender becomes of greater interest. Provided that the floor was cleaned in a short timeframe prior to the crime being committed (to ensure the relevance of the shoe marks found), the forensic scientist should have a look at the shoes of the employees. This reasoning process will continue beyond crime scene examination until the set of hypotheses are eventually restricted to the propositions of interest to the court, such as for instance "the shoe marks were deposited by the shoes of employee John Doe" versus "the shoe marks were deposited by another unknown pair of shoes".

\subsubsection{Methodological toolbox to apply hypothetico-deductive reasoning in practice and to reduce entropy throughout the process}

In contrast to the large interest dedicated to evidence evaluation in forensic science literature, conferences and guidelines, the first and mostly abductive parts of the forensic science process are less discussed and formalised. They are even sometimes disregarded as being scientific at all, despite strong philosophical arguments supporting historical thinking as a major and complex evidential reasoning that goes beyond inductivism and falsificationism [41-43]. We strongly believe that the scientific character of forensic science is not limited to the mostly deductive reasoning and mathematically formalised functions. Furthermore, we think it is dangerous to consider that when a forensic scientist operates as an investigator or is involved in intelligence, findings do not need to be processed and assessed with the perspective of scientific knowledge. We believe that such an attitude is hazardous as it leaves either the choice of providing factual or analytical results whose relevance may be nil, and may be misinterpreted by recipients, or the option of providing arbitrary assessments. Balance, scientific and inferential rigor as well as transparency should be applied to the complete scope of forensic science, from the crime scene to the courtroom or from the onset of treating a crime problem, whether findings are assessed formally or not, qualitatively or quantitatively. 
Despite their mostly tacit and qualitative nature, the most abductive parts of the forensic science process should not be regarded as a methodological terra incognita. At the crime scene, crime scripts [44] and the situational approach in criminology as well as to think like a criminal are useful means to guide the forensic scientist's action and thinking (i.e. to hypothesise what could have happened, finding the potential points of contact, detecting and collecting relevant traces) [45, 46]. The integration of traces (present or absent) into the forensic science process can proceed using crime intelligence analysis, which integrates mitigation of bias, visualisation methods (e.g. entityrelationship modelling and visualisation, chronologies and spatio/temporal analysis) and ways to manage and reason qualitatively on big data and large amount of traces $[47,48]$. The notions of frame and form [24] can assist in expressing and understanding the problem at hand by identifying the entities of interest (traces, persons, objects, places [49], time events [50], etc.) as well as their links. Hypotheses may also be developed from available observations through inference to the best explanation [51, 52]. In reference to the two systems of thinking described by Kahneman, the development of hypotheses calls unconsciously to intuition and heuristics, partly guided by experience and competence. On the other side, it uses cognitive efforts that require consciousness and concentration [53]. Analogical reasoning and associative activation are also likely to be pivotal in hypothesis development [53,54]. Systematic comparisons and the process of classification [55] are useful at these initial stages, in particular when searching indexes and databases, for instance to attribute a make and model to a shoe mark found at the crime scene, or to establish a list of compatible firearms from recovered cartridge cases. These are part of the various types of inference structures identified in conducting enquiries and treating crime problems, whose relevancy and modes of application depend on the circumstances of the case.

Along with the decrease in entropy and the progressively stronger emphasis on deduction, processing several hypotheses in parallel becomes a stronger challenge and requires more cognitive effort [56]. Forensic scientists may qualitatively refine the list of hypotheses through refutation (improbable scenarios can be set aside) or by mean of analysis of competing hypotheses, an approach developed by intelligence analysts [57]. The more we progress towards a more deductive attitude, the more quantitative and formal methods involving probabilities and a growing complexity begin to be of assistance, such as preliminary evaluative opinions, likelihood ratio assignments, full Bayesian assessments $[3,58]$. As will be shown in the example in section 3 , the critical success factor for the forensic science process is its ability to progress through qualitative and quantitative approaches and to combine them coherently.

Entropic situations and the management of several hypotheses in parallel generate cognitive and resource pressure on forensic scientists. It drives them naturally to prioritise decisions and actions that provide the largest decrease in entropy. This explains the general strategy to first try to exclude the hypothesis of a third-party intervention when investigating the scene of a crime. The exclusion of a third party significantly reduces the entropy (i.e. it reduces drastically and immediately the pool of potential offenders and scenarios). If a third party cannot be excluded, the focus is on the identification of a suspect. A notable exception to that rule is the so-called quick wins, namely hypotheses that are easily invalidated through a rapid, simple and inexpensive (forensic) examination. As an example, fire investigators often start with eliminating thunder as a possible cause of fire by checking weather reports, which takes less than a minute and is free of charge.

\subsection{The iterative nature of the continuous model}

The continuum underpinning the model should not be viewed as linear or as a monotonous decreasing function, but rather as iterative and cyclic. In short, reasoning is revisable. Inferences are regularly 
questioned and unmade when new observations/information contradicts previously inferred propositions.

First, a proper forensic process requires the capacity to anticipate as much as possible future issues along the process. Typically, forensic scientists at the crime scene must already think about issues that will eventually be disputed in front of the Court possibly years later [59]. Ideally, when the prosecution and the defence ultimately provide their respective scenarios, the forensic scientist should not be surprised if the investigation was conducted properly. Such an anticipation capacity is fundamental and relates to the notion of relevance [21] that guides a selective and efficient examination of crime scenes or of exhibits in the laboratory.

Second, when working on a case or on a criminal problem, observations, inferences and ideas are constantly updated, possibly highlighting pathways that were originally missed or misjudged. They come to mind either naturally or through a systematic process, but they should all be subjected to critical analysis and processed through a scientific approach and hypothetico-deductive reasoning. Any observation or inference may reopen closed doors at any time, or shed a different light on previous information or prior understanding. Reasoning is not unidirectional and requires forensic scientists to engage in iterative thinking and backtracking. Occasionally, there are also accelerations, redirections or ruptures in the reasoning process, for instance when a new piece of information causes a total change of vision on the case or the criminal problem.

Let us consider the investigation of the scene of the suspect death of an old man. After considering all the relevant hypotheses (natural death, accident, suicide or homicide, with all the associated manners of death), one may consider that the absence of break-in signs on the door, the absence of extraneous shoe marks in the premise, the advanced aged of the deceased and their position on the bed without any obvious sign of violence may favour the hypothesis of a natural death. The forensic scientist may then decide to examine the bathroom based on the hypothesis that the deceased could have taken medication or have vomited in the toilet. This examination could lead to the observation that the bathroom window was not completely closed and that an unexpected shoe mark was present on the windowsill. All of a sudden, the assessment of the different findings changes completely the way the scene and the case are investigated to find further (confirming or infirming) traces and information.

Iterative and cyclic reasoning is viewed as a success factor in criminal investigations [60]. For instance, research has shown that when crime scene examiners consider new information and update their reasoning, more accurate scenarios are obtained [15, 61]. Kind purposely used the notion of chapter to underline the smooth and possibly back-and-forth transitions between the phases of a criminal investigation [25]. However, coming back to a situation of higher entropy requires discipline since it might be difficult to accept that new data challenges the understanding and reconstruction of the events $[30,62]$. The strongest example of iterative reasoning and backtracking are cold case reexamination. A new team strives to start again from the beginning to recreate the entropy or original chaos that prevailed at the earliest stage of the initial investigation. In order to achieve success, past decisions have to be unmade, past inferences and hypotheses must be reviewed, revised or even discarded $[24,62,63]$.

\subsection{Decision points}

A multitude of decisions are made along the process. These decisions are not necessarily taken by the forensic scientist. In general, from the beginning of the process until the end, the forensic scientist progressively leaves the decision making to other actors [30]. The decision points summarised in figure 1 are not exhaustive but rather generic examples. One of the first decision point that occurs is whether 
an incident or problem is worth considering. If the answer is yes, a second decision point takes place: do we take action or do we attend the scene? For instance, if through the analysis of volume crimes (e.g. burglaries), a series is detected in a particular region, are we going to focus the resources on this particular problem and attend all the scenes in that particular region while running the risk of missing other problems? This is linked to the 'crime scene attendance' discussed in [64]. Once the decision is made to attend/investigate the scene, other decisions need to be made, such as how to delineate the crime scene. Where to focus attention and where not? Where to start? What and how to search? What to collect? What traces to process further (i.e. triage [64])? Which parameters to select to profile a trace [65]? Uncertainties at these decision points and the way these uncertainties are integrated in decision making processes can greatly vary amongst the various actors, as illustrated by York [66].

In contrast to the traditional view, decisions with the most important consequences are not necessarily at the end of the process, like in the courtroom [60]. For example, when operating on a suspect death scene, the decision to stop the examination because the most probable cause is considered natural or accidental rather than a homicide has dramatic consequences as there is usually no way back [67]. It is often said that crime scene processing is a one-time job that cannot be repeated, whereas appeals and revisions are common in criminal courts. A false exclusion during the earlier phases of an investigation may lead to never find the truth and, in judicial matters, never bringing the real offender to justice, and spend efforts on innocent targets. Another example is the inability to detect a series of homicides which could have dramatic consequences as the author has more chance to remain unidentified and continue his killings.

Decision points can have a punctual or recurrent nature in the forensic process. For instance, deciding whether or not to analyse a given drug specimen is a one-time decision point, while framing the population of interest during an investigation occurs each time a new piece of information emerges.

Any observation and inference, from the beginning to the end of the process, has to be assessed more or less formally. This will, in most cases, lead to a subsequent decision taken either by forensic scientists, or by other actors but based on information provided by a forensic scientist. Ribaux \& Caneppele gave an example using shoe marks on a crime scene [35]. A sequence of shoe marks on a crime scene may indicate that the perpetrator moved towards an object and touched it. This could lead to the collection of a fingermark on this object. The decision to collect the trace based on the sequence of shoe marks was deemed relevant at that time and was made independently of the role these shoe marks would play in Court. It is the risk, potential impact and consequences associated with these decisions that will differ along the continuum. Five key parameters - namely utility, credibility, integrity, timeliness and flexibility of forensic science outputs - are proposed to assist forensic scientists assess the strength and limits of their findings as well as guide their decision making.

Utility quantifies how desirable a possible outcome is. Mathematically speaking, expected utility and the principle of maximising it in a forensic science context has been discussed by Gittelson [68]. The expected satisfaction from each choice is assessed, and the choice with the greatest expected satisfaction is chosen. Here, satisfaction is defined by the decision-maker's objectives and preferences [69]. It must be understood as multidimensional, covering all forms of consequences and impact of the respective decision options, including Bitzer's utility defined as the informational added-value that may be obtained through the trace and its processing [70]. Key dimensions are resources (such as financial and manpower), potential errors, as well as the impact on privacy and fundamental rights. Concerning the latter, decisions and actions that limit the impact on privacy and fundamental rights (i.e. the least intrusive options) should be prioritised. For example, when faced with a DNA profile unknown to the national database, one might decide to engage in a mass screening, in a familial search 
(within government, private or public databases), or send the profile to the authorities of foreign countries for comparison. The third option comes with the least impact on privacy.

Regarding potential errors, two competing parameters always affect a decision. Credibility depends on the ability to limit erroneous positive information (measured through type I errors) [65]. When performing geographical profiling in order to locate a serial offender, forensic case data can be pivotal to weigh the strength of the association between each case and the crime series. This increases geographic profiling accuracy, as shown in the investigation of a serial rapist and murderer in Las Vegas where it was decided to give higher weight to cases connected to the series based on DNA and fingermarks [71]. In such a situation, the forensic scientist needs to maximise credibility (over integrity) since the decision to include one or several cases in a series with a limited probability of association may significantly bias and alter the accuracy of geographic profiling [72]. Conversely, integrity is the ability to limit the erroneous negative information (measured through type II errors) [65]. For example, when deciding to apply a low stringency search in a DNA database, integrity is sought to avoid missing any potential sources. Forensic IT analysts usually decide to maximise integrity when they search and extract images with potential paedophile content on a computer or smartphone. The aim is not to miss reporting any potential illegal content to the investigators, who will have to formally assess the legality of those images and process the case further. In every situation, a balance has to be struck between credibility and integrity.

Timeliness (or the time factor) is the ability to make or support decisions in a timely manner [65]. For instance, decisions might be constrained by deadlines fixed by the criminal justice system, such as police custody prior to being formally accused (typically 24 hours in the UK and Switzerland). This necessarily has an impact on the forensic scientist's work and decisions. During that time, it is not possible to conduct most laboratory analyses and interpretation of the results. The time available to decide - ranging from microseconds to months - will have an impact on engaging in more or less formal decisions, from the most intuitive, immediate and tacit to the most rigorous, mathematical and explicit [53].

Flexibility is the ability of the forensic scientist to adapt to and account for the different contexts in which they operate and decide, the various stakeholders they are operating and deciding with, the crime environment and its evolution [12]. Decisions will depend on strategic issues, organisational priorities and culture, the jurisdiction and its rules, pressures, as well as social aspects between decision-makers and team members [60]. As is illustrated in section 3 , a given forensic finding may be used in various contexts, and flexibility is required.

Consideration of these five parameters constitute a forensic scientist fundamental knowledge base, necessary to address decision points at different times in the continuum in order to obtain the most relevant and reliable information. We advocate that generic and/or key decision points could be formalised more extensively and should be the topic of research in order to better inform decisionmaking in forensic science.

\subsection{Alternative information and collaboration}

Forensic science does not exist in isolation, and forensic findings are pointless in isolation [2]. All the observations, hypotheses and decisions made along the continuum interact with alternative information (which may be genuine or fake) such as crime intelligence, open source information, witnesses' and suspects' interviews, (false) confessions, informants, whistle-blowers, as well as other fields of knowledge such as criminology. For example, from an intelligence-led policing perspective, understanding the regional criminal activity and its structure might influence the decision to attend a 
particular crime scene if the case is inferred to belong to a particular series or crime phenomenon. This might thus increase the propensity to investigate this scene and engage in further forensic efforts $[40,45,46]$. Understanding the criminal problem at stake based on alternative information might also influence the type of traces collected [40,64], even if their quality is low since they participate to the explanation of the event, and information obtained from witnesses or victims, or from CCTV footages, can also provide clues about relevant traces [73]. Alternative information is also taken into account in the Bayesian interpretation framework, usually introduced as conditioning information and abbreviated by the letter $I$ in the mathematical notation $[68,74-76]$. Hence, the forensic findings exist within a context and relate to many alternative pieces of information, constituting in most cases a "faisceau d'indices" (i.e. a number of clues that point to the same conclusion but are not sufficient on their own, translated as "corroborating evidence", "a consistent body of evidence" or a "common cause explanation" [77]). For these reasons, a holistic vision and a collective approach to problemsolving constitute the essential basis of forensic science endeavours with no limits in the dimensions considered (i.e. spatial, temporal, relational and quantitative) [47, 69]. Forensic scientists should therefore identify and interact with relevant alternative information, collaborate with various stakeholders, delineate and connect respective contributions, and be conscious of the risk of contextual bias, rather than inefficiently producing data under vacuum. The proposed model facilitates the implementation of such an approach and provides guidance for interactions. For instance, it provides support for defining various roles in forensic practice that fill some of the gaps, such as that of 'forensic advisors'. Forensic advisors were created by forensic laboratories in an increasing number of countries and "act as an advising body to the magistrate to improve communication between the various parties involved in the investigation: magistrate, police and crime scene investigators, and forensic experts" $[78,79]$.

The relationship between entropy and being able to distinguish task relevant from task irrelevant alternative information is a promising approach to conciliate opposing views around alternative information and bias, i.e. those who favour isolating forensic scientists versus those who favour integrating forensic scientists as much as possible with others stakeholders and their information [80]. The distinction between task relevant and task irrelevant information is easier to make as entropy decreases [76]. When entropy is at its highest, no distinction can be made between task relevant and task irrelevant information, and as a result, all information is taken into account. This behaviour is seen at the beginning of the forensic process (typically at the crime scene) when the forensic scientists crave information, including form other stakeholders, to rationally progress in the mist or fog. Every piece of information they obtain is used to frame the problem, ask questions, and guide the decisions. Then, as entropy decreases, the forensic scientists decide to conduct a number of forensic analyses to advance the case. For each of these, a distinction appears between task relevant information and task irrelevant information. The information classified as task irrelevant is the information that the forensic scientists will want to avoid in order to provide a neutral and transparent evaluation of their observations resulting from a particular analysis (e.g. the results of other forensic analyses, confessions, and any other information that would lead them to think that one proposition is true).

\section{Example to illustrate the model}

One evening at the end of January, forensic scientists were called by a police patrol to investigate the scene of a house burglary (case 1). One of the windows was broken. Based on the short description of the case provided by the patrol officer, their own experience, general knowledge of crime, and education in criminology and crime science, the first hypothesis that came to the forensic scientists' mind is that such a case could be associated to the phenomenon of twilight burglaries, common in the wintertime. Such burglaries are often serial and committed by professional and prolific offenders. 
Crime intelligence thus guided forensic observations and inferences. On the way to the scene, the forensic scientists decided to put an emphasis on integrity ${ }^{4}$ while remaining critical and ready to test the initial hypothesis. An open-minded approach should keep open other possibilities such as facing an isolated rather than a serial case, a staged burglary, or a burglary that ended up as a homicide. If serial, the case could be the beginning of a series or part of a pre-existing one. Prior to any forensic observations and inferences, entropy was at its highest.

After having examined the crime scene, the forensic scientists observed and collected shoe marks associated with two different patterns, A and B (Figure 3). Such marks supported the development of hypotheses regarding the number of offenders (at least 2 people), their respective activities and participation in the offence, as well as the paths taken. As mentioned in section 2.4 , these paths may guide the search of other types of traces, such as fingermarks or biological traces. The overall observations conducted by the forensic scientists as well as alternative information confirmed the initial hypothesis that the case was a twilight burglary (according to a situational analysis of the case: the modus operandi, point of entry, target, and spatiotemporal information).

In the laboratory, the forensic scientists compared both shoe mark patterns against the case management database, but did not find any similar patterns. This infirmed the hypothesis of a serial crime, at least temporarily. The forensic scientists decided to consider the case as isolated and not to put any particular effort in analysing further traces.

The following evening, another twilight burglary was reported (case 2 ) and investigated by another forensic scientist team, who collected two shoe marks, patterns B and C. In the laboratory, thanks to a comparison in the database, the marks were found to be similar to pattern $\mathrm{B}$ recovered in case 1 whereas pattern $\mathrm{C}$ did not show any similarities with any marks in the database. The detection of a trace link between two similar types of cases offered a new perspective and the possibility to revive by inference that the investigation was faced with a series, the importance of which led to deeper analyses. It was decided to link cases 1 and 2, creating series Z. That proposition alerted both scientists and law enforcement services. The event of a third twilight burglary, case 3, strengthened the perceived situation when shoe marks of pattern $B$ and $C$ were detected. Based on these observations and convergent alternative information, the forensic scientists suggested two reasonable scenarios that series $Z$ was perpetrated by two or three offenders (depending on whether shoe marks $A$ and $C$ could be a shoe change for one offender between the first and the second evening).

\footnotetext{
${ }^{4}$ The emphasis on integrity is to avoid missing any relevant traces since the case is hypothesised to be serial and therefore of higher interest. For instance, the forensic scientist might decide to collect more shoe marks (including lower quality or apparently less relevant ones), taking the risk of collecting traces that would not be collected in a case not considered as serial. Such a position can change during the crime scene examination, if necessary.
} 


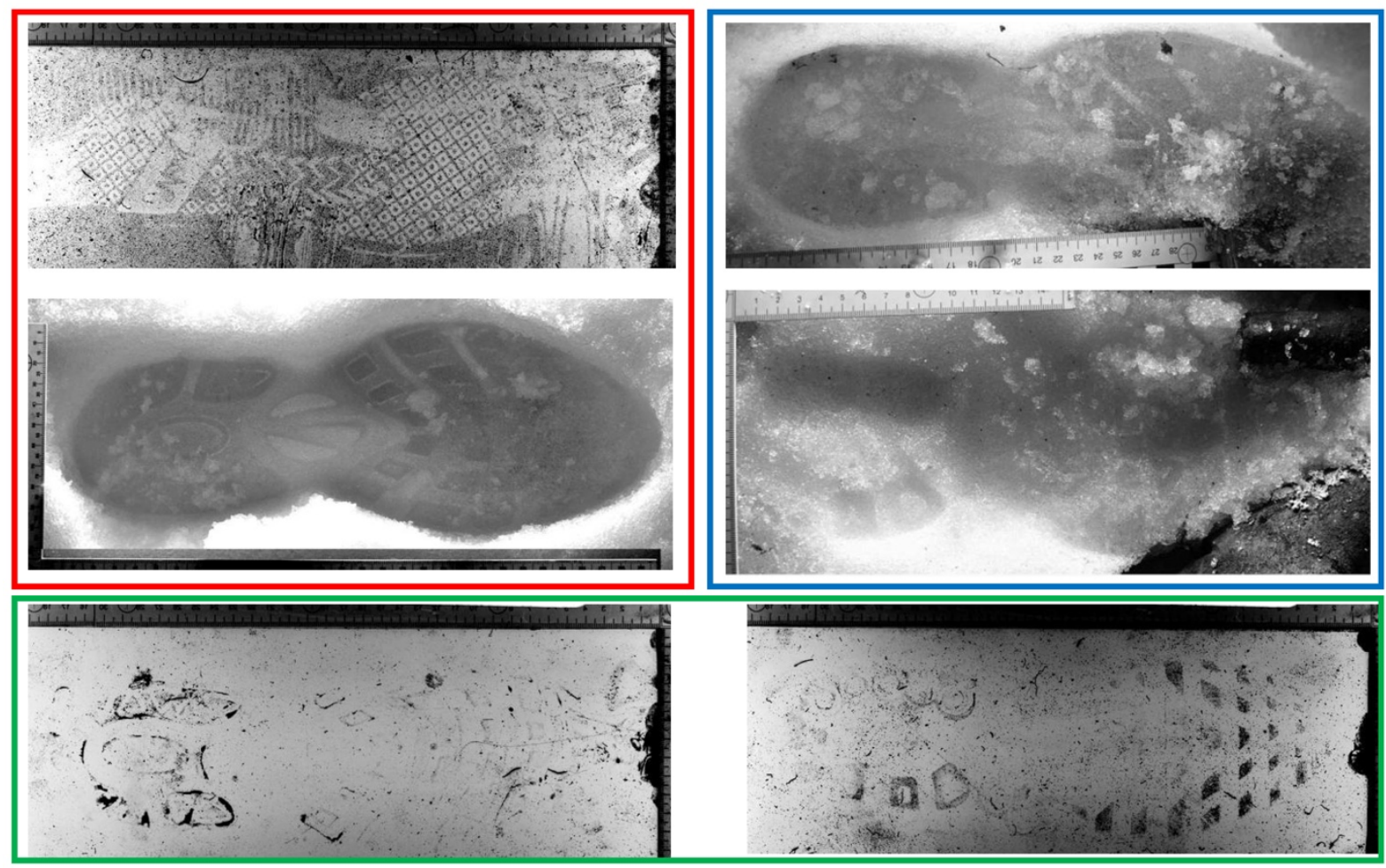

Figure 3. Shoe marks collected at the scenes of case 1 (red, A top and B bottom), case 2 (blue, B top and $C$ bottom), and case 3 (green, $B$ left and $C$ right).

Considering the serial character of the burglaries, forensic scientists decided to process the various traces collected on the different scenes and to report results to investigators and crime analysts. It was collectively decided to engage in an active monitoring of series $Z$ and twilight burglaries in general. Thanks to shoe and tool mark comparisons, combined with spatiotemporal analysis, around ten more cases were added to series $Z$ in the following days and weeks. A relational chart was produced and kept up to date to follow-up on new or revised information. At that point, integrity was judged more important than credibility when deciding whether or not to include a case in series $Z$. The intent was not to miss any potentially linked cases. No impact on privacy was involved, and no adverse consequences (utility) could occur at this point since the analysis was conducted within a small team made up of well-informed colleagues.

In parallel, knowing the serial and cross-jurisdictional nature of the type of crime under investigation, forensic scientists developed the hypothesis that the series might extend beyond their current perception. They decided to compare their shoe marks with shoe marks collected in neighbouring jurisdictions. Based on trace-to-trace comparisons, twenty more twilight burglaries committed in 4 other jurisdictions were linked to series Z. Interestingly, a third of these twenty cases had been committed prior to case 1 , showing that the series was pre-existent but remained unseen.

In mid-February, DNA analysis results started to come back progressively. Many DNA profiles (full, partial and mixed) were obtained from traces recovered from several twilight burglaries crime scenes. Some profiles connected ten further burglaries to this series $Z$, and confirmed the pre-existing links of five other cases. At that stage, likelihood ratio evaluations of trace-to-trace comparisons were deemed important for partial and mixed DNA profiles in order to decide whether or not each case should be kept in the series or excluded. The purpose of which, at this point, was to put a stronger emphasis on credibility by removing potential false positives (i.e. cases that were not connected to series $Z$ ). These trace-to-trace DNA links connected twilight burglaries committed around a similar timeframe, except 
for one burglary that had been committed in a factory two years earlier. The latter did not have the same circumstantial features as series $Z$, which raised questions and resulted in an increase in entropy. It was hypothesised that either an offender had visited both locations, or a person had been present in both locations legitimately. The hypotheses were tested, and the individual at the source of both DNA specimens was found to be a legitimate occupant of both locations (family house and work). Thanks to this control, not neutral in terms of privacy and costs, the DNA profile and the observed link could be deemed irrelevant and excluded from the series, and the entropy decreased.

Some profiles recovered in different cases associated with series $Z$ were sent to the national DNA database, but no hit to a person was reported. In order to assess the number of offenders committing series $Z$, the investigation team decided to consider only recurrent profiles, namely those that appeared in at least two cases. That criterion maximises the credibility of remaining DNA profiles since it excludes the contamination/pollution profiles due to victims, inhabitants or policemen (forensic scientists and lab analysts are registered in a DNA staff index and could be excluded rapidly). Of course, integrity was affected since it may miss relevant but non-recurrent DNA profiles. Three different DNA profiles emerged, suggesting that (at least) 3 offenders were perpetrating series $Z$.

Furthermore, DNA results linked burglaries where different shoe mark patterns had been recovered. Two alternative hypotheses were developed and tested, namely that a same group of three offenders were changing their shoes (demonstrating professionalism in committing burglaries by trying to disrupt forensic investigations, pointing to the hypothesis of recidivists), or that three 'core offenders' had committed burglaries with various accomplices. Different combinations of shoe mark patterns were observed and constituted successive clusters of cases over time. Based on this observation and alternative information, the first hypothesis was considered more probable, i.e. that the authors were recidivists, which considerably reduced the entropy, but also engaged the inquiry in a specific direction with some uncertainty.

Based on these findings and inferences, it was judged likely that these offenders would strike again. The investigation team decided to set up targeted surveillance based on forensic links and geographical profiling (see section 2.4). Maximal credibility was sought to avoid misguiding surveillance efforts. A few days later, at the beginning of March, a group of burglars were surprised by a witness and fled the scene of an attempted twilight burglary. The increased number of surveillance patrols in this area led to a car chase followed by an accident. Two out of the three occupants of the car were caught, with the third one on the run.

Thanks to the trace comparison and interpretation efforts conducted by the forensic science team form the start and prior to any arrest, a strong case could be built quickly during the police custody period (parameter timeliness). Moreover, forensic findings assisted investigators and the magistrate to decide on their interview strategy. When interviewed, both arrestees only confessed to three house burglaries committed the night of the arrest. Both denied being involved in the series. The pattern of one of the pair of shoes worn by the arrestees was similar to patterns observed in seven cases associated with series Z. Coming back to the successive clusters of cases depicted by the shoe mark comparisons, the timeline of the series could be built and described in a retrodictive fashion. The strength of the analysis could be tested by DNA results as well as alternative information, such as phone call analysis and witness testimonies. After a few days, DNA results confirmed that the arrestees' DNA profiles were indistinguishable from two of the three recurrent DNA profiles across series Z. Despite that, many cases in the series were solely linked on the basis of shoe marks without a direct association with a person, and these links were judged tenuous. In consultation with the magistrate, considering the entropy was still too high, it was decided to formally evaluate not only 
the trace-to-shoe comparison results, but also the trace-to-trace comparison results and to present these likelihood ratios in the final report.

In the end, the combination of the forensic findings and the alternative information supported the proposition or story line that a prolific and professional group of 3 offenders shared responsibility for about 50 independent home burglaries committed across five jurisdictions within a timeframe of 41 days. Based on the report presenting the above-mentioned forensic results and their evaluation, as well as the overall reasoning and logic applied, both arrestees were convicted by the Court and, later, in appeal. At this point, entropy was at its lowest. Beyond this, the work performed on series $Z$ was used to update crime intelligence and general knowledge about twilight burglaries (i.e. the continuum is iterative and cyclic).

This example shows the multiple contributions of forensic traces and observations along a non-linear continuum, with some fast advances offered by perceived elements that decrease the entropy of a given situation, with reflecting pauses, revisions, iterations, even ruptures when contradictory results are found. The contributions may be used at different moments in the process and within different contexts and in support to various decision points. This illustration did not address every decision point or hypothesis development and testing since this would require too long of a narrative for this paper. However, the example showcases the highly intertwined character of intelligence and evidence, investigation and evaluation as well as the high intellectual demand created by the uncertainty resulting from the asymmetry of time and events.

\section{Conclusion}

This paper is a reflection on fundamental questions about the role of forensic science in general and how it fits in a scientific paradigm beyond the traditional, often narrowly defined, concepts of intelligence, investigation and evaluation. The model proposed attempts to provide guidance on how forensic scientists may value, situate and integrate their contribution at any point to approach and address a case, criminal problem or phenomenon. It may serve as a guide for the reasoning process of forensic scientists since "understanding this grey scale offered by trace findings, and how they can feed the other processes (investigation, intelligence, prevention, court proceedings, etc.) is what forensic science is about" [81]. This continuous model fosters an over-arching forensic framework and sheds light on the interface of multiple sub-disciplines and tasks in forensic science, some of which may be distributed to different specialised individuals, but that must remain connected to the whole in a generalist and holistic perspective $[2,79]$. A sound management of these overlapping zones is a critical success factor of the forensic science process and a means to avoid miscarriages of justice [5, 82]. Unfortunately, these zones are systematically overlooked when forensic science is put under scrutiny by insiders or external observers. For instance, the PCAST report [83] and the decisions that followed it challenged the forensic use of shoe marks, failing to consider its powerful contribution to investigative and intelligence efforts, which play a decisive role in solving serious and serial crimes.

Instead of defining forensic science through organisational considerations, this model abstracts itself from the organisation and focuses on the scientific concepts that can be applied worldwide. This model has the potential to provide coherence and strengthens the identity of forensic science by clarifying its scope and position within an environment involving a number of stakeholders and various contexts. It could help reduce the tensions and clarify the dynamic and complex interactions between crime scene and laboratory activities, scientific findings and alternative information, investigations and evaluations, as well as intelligence and evidence. In this perspective, the model is a first attempt to pave a way forward for forensic laboratories to escape the Kodak syndrome by "expand[ing] their field of view beyond courtrooms, and adopt a much more investigative focus" [84]. 
Beyond forensic science, the model is compatible with more general paradigms regarding criminal investigation, intelligence analysis or policing [33, 69, 85-87]. Specifically, the model, its underpinning continuum and the three-chapter paradigm of criminal investigation proposed by several authors converge very well - that is, if we consider that there is a fourth preliminary chapter that we define as detection $[25,88-90]$. Therefore, the model provides a useful basis as to how forensic scientists can contribute to collective and collaborative problem-solving to improve justice and security. This view creates the necessity of true forensic science education, training and research since the discipline cannot rely on excellent specialists of various disciplines to develop the semiology, philosophies and reasoning processes.

Finally, the model identifies research gaps, namely decision points and their underlying parameters, the integration of the forensic process within modern and proactive forms of policing, as well as the impact of digitalisation on forensic science. The latter will indisputably be a catalyst and incentive to break - or open - even more the pre-existing barriers [91].

\section{References}

[1] Roux C., Crispino, F., Ribaux, O. (2012), Forensics to forensic science, Current Issues in Criminal Justice, 24, 7-24.

[2] San Pietro D., Kammrath B. W., De Forest P. R. (2019), Is forensic science in danger of extinction?, Science \& Justice, 59, 199-202.

[3] Jackson G., Jones S., Booth G., Champod C., Evett I. W. (2006), The nature of forensic science opinion-a possible framework to guide thinking and practicce in investigation and in court proceedings, Science \& Justice, 46, 33-44.

[4] Margot P. (2011), Forensic science on trial - what is the law of the land?, Australian Journal of Forensic Sciences, 43, 89-103.

[5] Barclay D. (2009), Using forensic science in major crime inquiries, In: Handbook of forensic science, Fraser, J., Williams, R., Eds., Willan Publishing: Devon.

[6] Machado H., Granja R. (2018), Ethics in transnational forensic DNA data exchange in the eu: Constructing boundaries and managing controversies, Science as Culture, 27, 242-264.

[7] Egger S. A. (1984), Working definition of serial murder and the reduction of linkage blindness, Journal of Police Science and Administration, 12, 348-357.

[8] Kean T. H., Hamilton L. (2004), The 9/11 commission report: Final report of the national commission on terrorist attacks upon the united states, National Commission on Terrorist Attacks upon the United States, Washington, D.C.

[9] United Nations (2011), Criminal intelligence manual for analysts; United Nations Office on Drugs and Crime Vienna, Ed.; United Nations: Vienna.

[10] ENFSI (2015), Strenghtening the evaluation of forensic results across europe.

[11] National Institute of Forensic Science Australia New Zealand (2017), An introductory guide to evaluative reporting, National Institute of Forensic Science Australia New Zealand, Melbourne.

[12] Onwuegbuzie A. J., Leech N. L. (2005), On becoming a pragmatic researcher: The importance of combining quantitative and qualitative research methodologies, International Journal of Social Research Methodology, 8, 375-387.

[13] Buckler K. (2008), The quantitative/qualitative divide revisited: A study of published research, doctoral program curricula, and journal editor perceptions, Journal of Criminal Justice Education, 19, 383-403.

[14] Jacques S. (2014), The quantitative-qualitative divide in criminology: A theory of ideas' importance, attractiveness, and publication, Theoretical Criminology, 18, 317-334.

[15] de Gruijter M., Nee C., de Poot C. J. (2017), Identification at the crime scene: The sooner, the better? The interpretation of rapid identification information by csis at the crime scene, Science \& Justice, 57, 296-306. 
[16] Evett I. (2015), The logical foundations of forensic science: Towards reliable knowledge, Philosophical Transactions of the Royal Society B: Biological Sciences, 370, 20140263.

[17] DeHaan J. D. (2008), Stuart kind memorial lecture. Forensic science society. November 2, 2007, Science \& Justice, 48, 91-94.

[18] Roux C., Talbot-Wright B., Robertson J., Crispino F., Ribaux O. (2015), The end of the (forensic science) world as we know it? The example of trace evidence, Philosophical transactions of the Royal Society of London. Series B, Biological sciences, 370, 20140260.

[19] Morgan R. M. (2017), Conceptualising forensic science and forensic reconstruction. Part i: A conceptual model, Science \& Justice, 57, 455-459.

[20] Morgan R. M. (2017), Conceptualising forensic science and forensic reconstruction. Part ii: The critical interaction between research, policy/law and practice, Science \& Justice, 57, 460-467.

[21] Hazard D. (2016), The relevant physical trace in criminal investigation, Journal of Forensic Science and Medicine, 2, 208-212.

[22] Locard E. (1920), L'enquête criminelle et les méthodes scientifiques: Paris.

[23] De Forest P. R. (1999), Recapturing the essence of criminalistics, Science \& Justice, 39, 196-

208.

[24] Kind S. S. (1987), The scientific investigation of crime, Forensic Science Services Ltd: Harrogate.

[25] Kind S. (1994), Crime investigation and the criminal trial: A three chapter paradigm of evidence, Journal of the forensic science society, 34, 155-164.

[26] Favretti M. (2018), Remarks on the maximum entropy principle with application to the maximum entropy theory of ecology, Entropy, 20, 11.

[27] Margot P. (2011), Commentary on the need for a research culture in the forensic sciences, UCLA Law Review, 58, 795-802.

[28] Von Clausewitz C. (1832), On war, Princeton University Press: Princeton, New Jersey.

[29] Guéniat O. (2017), In vestige @ and police management?, Policing: A journal of Policy and Practice, 1-12.

[30] Ribaux O. (2014), Police scientifique, le renseignement par la trace, Presses polytechniques et universitaires romandes: Lausanne.

[31] Jamieson A. (2004), A rational approach to the principles and practice of crime scene investigation: I. Principles, Science \& Justice, 44, 3-7.

[32] Nordby J. J. (2000), Dead reckoning: The art of detection, CRC Press: Boca Raton, Florida.

[33] Harris D. H. (2012), Critical thinking training for intelligence analysis, IALEIA journal, 20, 76-

88.

[34] Le raisonnement et la logique des choses; Peirce C. S., Ed.; Les Editions du Cerf: Paris, 1995.

[35] Ribaux O., Caneppele S. (2018), Forensic intelligence, In: The routledge international handbook of forensic intelligence and criminology, Rossy, Q., Décary-Hétu, D., Delémont, O., Mulone, M., Eds., Routledge Taylor \& Francis Group: London and New York; pp 137-148.

[36] Atkin H. N. (1998), Keep it simple: A practitioners approach to applying; the intelligence process, from formulating premises to recommendations, IALEIA journal, 11, 1-11.

[37] Kelty S. F., Julian R., Robertson J. (2011), Professionalism in crime scene examination: The seven key attributes of top crime scene examiners, Forensic Science Policy \& Management: An International Journal, 2, 175-186.

[38] Carson D. (2009), The abduction of sherlock holmes, International Journal of Police Science \& Management, 11, 193-202.

[39] Rossy Q. (2011), Méthodes de visualisation en analyse criminelle: Approache générale de conception des schémas relationnels et développement d'un catalogue de patterns, Facutlé de Droit et des Sciences Criminelles de l'Université de Lausanne, University of Lausanne.

[40] Resnikoff T., Ribaux O., Baylon A., Jendly M., Rossy Q. (2015), The polymorphism of crime scene investigation: An exploratory analysis of the influence of crime and forensic intelligence on decisions made by crime scene examiners, Forensic Science International, 257, 425-434. 
[41] Harrison K. (2006), Is crime scene examination science, and does it matter anyway?, Science \& Justice, 46, 65-68.

[42] Ribaux O., Roux C., Crispino F. (2017), Expressing the value of forensic science in policing, Australian Journal of Forensic Sciences, 49, 489-501.

[43] Cleland C. E. (2013), Common cause explanation and the search for a smoking gun, In: Rethinking the fabric of geology, Baker, V. R., Ed., The Geological Society of America, Vol. 502; pp 19.

[44] Leclerc B. (2016), Crime scripts, In: Environmental criminology and crime analysis, 2 nd ed., Wortley, R., Townsley, M., Eds., Routledge: London; pp 119-141.

[45] Ribaux O., Baylon A., Roux C., Delémont O., Lock E., Zingg C., Margot P. (2010), Intelligenceled crime scene processing. Part i: Forensic intelligence, Forensic Science International, 195, 10-16.

[46] Ribaux O., Baylon A., Lock E., Delémont O., Roux C., Zingg C., Margot P. (2010), Intelligenceled crime scene processing. Part ii: Intelligence and crime scene examination, Forensic Science International, 199, 63-71.

[47] Rossy Q., Ribaux O. (2014), A collaborative approach for incorporating forensic case data into crime investigation using criminal intelligence analysis and visualisation, Science \& Justice, 54, 146-153.

[48] Rossy Q., Morselli C. (2018), The contribution of forensic science to the analysis of crime networks, In: The routledge international handbook of forensic intelligence and criminology, Rossy, Q., Décary Hétu, D., Delémont, O., Mulone, M., Eds., Routledge Taylor \& Francis Group: London and New York; pp 191-204.

[49] Baechler S., Caneppele S. (2018), Exploratory spatial data methodologies: How they can be used to analyse forensic case data, In: The routledge international handbook of forensic intelligence and criminology, Rossy, Q., Décary Hétu, D., Delémont, O., Mulone, M., Eds., Routledge Taylor \& Francis Group: London and New York; pp 212-224.

[50] Weyermann C., Ribaux O. (2012), Situating forensic traces in time, Science \& Justice, 52.

[51] Lipton P. (2004), Inference to the best explanation, Psychology Press.

[52] Harman G. H. (1965), The inference to the best explanation, Philosophical Review, 74, 88-95.

[53] Kahneman D. (2011), Thinking, fast and slow, Farrer, Straus and Giroux: New York.

[54] Hofstadter D. R., Sander E. (2013), Surfaces and essences: Analogy as the fuel and fire of thinking, Basic Books.

[55] Inman K., Rudin N. (2002), The origin of evidence, Forensic Science International, 126, 11-16.

[56] Pottier P., Planchon, B. (2011), Les activités mentales au cours du raisonnement médical diagnostique, La revue de médecine interne, 32, 383-390.

[57] Heuer R. J. (1999), Psychology of intelligence analysis, Central Intelligence Agency.

[58] Taroni F., Aitken C. G. G., Garbolino P., Biedermann A. (2006), Bayesian networks and probabilistic inference in forensic science, John Wiley \& Sons, Ltd: Chichester.

[59] Julian R., Robertson J. (2011), Professionalism in crime scene examination: The seven key attributes of top crime scene examiners au - kelty, sally f, Forensic Science Policy \& Management: An International Journal, 2, 175-186.

[60] Salet R. (2017), Framing in criminal investigation:How police officers (re)construct a crime, The Police Journal, 90, 128-142.

[61] de Gruijter M., de Poot C., Elffers H. (2017), Reconstructing with trace information: Does rapid identification information lead to better crime reconstructions?, Journal of Investigative Psychology and Offender Profiling, 14, 88-103.

[62] Salet R., Terpstra J. (2013), Critical review in criminal investigation: Evaluation of a measure to prevent tunnel vision, Policing: A journal of Policy and Practice, 8, 43-50.

[63] Gaylor D. (2002), Getting away with murder: The re-investigation of historic undetected homicide, Sussex Police.

[64] Delémont O., Bitzer S., Jendly M., Ribaux O. (2018), The practice of crime scene examination in an intelligence-based perspective, In: The routledge international handbook of forensic 
intelligence and criminology, Rossy, Q., Décary-Hétu, D., Delémont, O., Mulone, M., Eds., Routledge Taylor \& Francis Group: London and New York; pp 86-101.

[65] Baechler S., Morelato M., Ribaux O., Beavis A., Tahtouh M., Kirkbride P., Esseiva P., Margot P., Roux C. (2015), Forensic intelligence framework. Part ii: Study of the main generic building blocks and challenges through the examples of illicit drugs and false identity documents monitoring, Forensic Science International, 250, 44-52.

[66] York C. A. (2011), Anzfss symposium, Australian Journal of Forensic Sciences, 43, 85-88.

[67] Jackowski C., Hausmann R., Jositsch D. (2014), Eine dunkelziffer bei tötungsdelikten in der schweiz. Fiktion oder realität? , Kriminalistik, 68, 607-614.

[68] Gittelson S. N. (2013), Evolving from inferences to decisions in the interpretation of scientific evidence, Ecole des sciences criminelles, University of Lausanne.

[69] Aepli P., Ribaux O., Summerfield E. (2011), Decision making in policing, EPFL Press: Lausanne.

[70] Bitzer S., Ribaux O., Albertini N., Delémont O. (2016), To analyse a trace or not? Evaluating the decision-making process in the criminal investigation, Forensic Science International, 262, 1-10.

[71] Canter D., Coffey T., Huntley M., Missen C. (2000), Predicting serial killers' home base using a decision support system, Journal of Quantitative Criminology, 16, 457-478.

[72] Ruffell A., McKinley J. (2008), Geoforensics, John Wiley \& Sons: Chichester, UK.

[73] Wyatt D. (2014), Practising crime scene investigation: Trace and contamination in routine work, Policing and Society, 24, 443-458.

[74] Aitken C. G. G., Taroni F. (2004), Statistics and the evaluation of evidence for forensic scientists; 2nd ed., John Wiley \& Sons Ltd: Chichester.

[75] Evett I. W., Weir B. S. (1998), Interpreting DNA evidence, Sinaur Associates: Sunderland.

[76] National Commission on Forensic Science (NCFS) (2015), Ensuring that forensic analysis is based upon task-relevant information, U.S. Department of Justice, Washington DC.

[77] Cleland C. E. (2011), Prediction and explanation in historical natural science, British Journal of the Philosophy of Science, 62, 551-582.

[78] Bitzer S., Heudt L., Barret A., George L., Van Dijk K., Gason F., Renard B. (2018), The introduction of forensic advisors in belgium and their role in the criminal justice system, Science \& Justice, 58, 177-184.

[79] Bitzer S. (2019), Forensic case coordination in europe - their role within 5 european institutes, Forensic Science International, 300, 1-5.

[80] Champod C. (2014), Research focused mainly on bias will paralyse forensic science, Science \& Justice, 54, 107-109.

[81] Margot P. (2018), Traceology, the bedrock of forensic science and its associated semantics, In: The routledge international handbook of forensic intelligence and criminology, Rossy, Q., DécaryHétu, D., Delémont, O., Mulone, M., Eds., Routledge Taylor \& Francis Group: London and New York; pp 30-39.

[82] Gould J. B., Carrano J., Leo R., Young J. (2012), Predicting erroneous convictions: A social science approach to miscarriages of justice.

[83] PCAST (2016), Forensic science in criminal courts: Ensuring scientific validity of featurecomparison methods; Executive Office of the President President's Council of Advisors on Science and Technology Committee, Ed.: Washington.

[84] Casey E., Ribaux O., Roux C. (2019), The kodak syndrome: Risks and opportunities created by decentralization of forensic capabilities, Journal of Forensic Sciences, 64, 127-136.

[85] Ratcliffe J. H. (2007), Integrated intelligence and crime analysis: Enhanced information management for law enforcement leaders; U.S. Department of Justice, Ed.; Police Foundation: Washington.

[86] National Academies of Sciences Engineering and Medicine (2018), Proactive policing: Effects on crime and communities, The National Academies Press: Washington, DC.

[87] National Centre for Policing Excellence (2005), Practice advice on core investigative doctrine, Association of Chief Police Officers Centrex, Cambourne. 
[88] Brodeur J.-P. (2005), L'enquête criminelle, Criminologie, 38, 39-64.

[89] Simms B. W., Petersen E. R. (1991), An information processing model of a police organization, Management Science, 37, 216-232.

[90] Morelato M., Baechler S., Ribaux O., Beavis A., Tahtouh M., Kirkbride P., Roux C., Margot P. (2014), Forensic intelligence framework - part i: Induction of a transversal model by comparing illicit drugs and false identity documents monitoring, Forensic Science International, 236, 181-190.

[91] Casey E., Katz G., Lewthwaite J. (2013), Honing digital forensic processes, Digital Investigation, 10, 138-147. 